\title{
Innovation and organisation in the UK magazine print publishing industry: a survey
}

\author{
Howard Cox \\ Head of the Graduate School, \\ University of Worcester, \\ Henwick Grove, \\ Worcester \\ WR2 6AJ, UK \\ E-mail: h.cox@worc.ac.uk
}

\section{Simon Mowatt*}

Faculty of Business, Auckland University of Technology, Private Bag 92006, Auckland 1020, New Zealand

Fax: +64 099179884 E-mail: simon.mowart@aut.ac.nz

*Corresponding author

\section{Stuart Young}

Applied Mathematics, Auckland University of Technology, Private Bag 92006, Auckland 1020, New Zealand

E-mail: stuart.young@aut.ac.nz

\begin{abstract}
This paper examines innovation within the UK magazine publishing industry. We find that publishers are able to engage with niche interest groups in order to supply a high value-added product. The paper attempts define the characteristics of the industry and to examine the drivers of innovation through a survey and an exploratory approach to data analysis. We suggest that the frequently employed simple output measures of innovation do not adequately capture the innovation process in this industry or the range of activities carried out by firms. We find that groups of firms engage different patterns of innovative depending on the drivers of innovation. Firms that are more responsive to consumer trends and more likely to engage in a wider range of associated activities in order to add value from their consumer knowledge.
\end{abstract}

Keywords: printing and publishing; industry surveys; information age; innovation.

Reference to this paper should be made as follows: Cox, H., Mowatt, S. and Young, S. (2005) 'Innovation and organisation in the UK magazine print publishing industry: a survey', Global Business and Economics Review, Vo!. 7, No. 1, pp.11l-127. 
Biographical notes: Professor Howard Cox is Head of the Graduate School at the University College Worcester, UK. He has published widely in the field of Business and Economics, having published the OUP monograph The Global Cigarette and in journals such as Business History, The Business Economist and Industrial and Corporate Change.

Dr. Simon Mowatt is Senior Research Lecturer in the Faculty of Business at Auckland University of Technology, New Zealand and visiting fellow at the Centre for International Business History at the University of Reading, UK. His research examines business networks, competition and industrial transformation in historical context. He received the IBM prize for best paper at the 2002 E-Business Conference (with Howard Cox) and has published widely in journals such as Industry and Innovation, Industrial and Corporate Change and Qualitative Market Research: An International Journal.

Stuart Young is Senior Lecturer in Applied Mathematics at the Auckland University of Technology, New Zealand. His interest is in Statistical Analysis and Quantitative Research.

\section{Introduction}

This paper presents the results of a questionnaire carried out during the first half of 2002 designed to investigate changing patterns of innovation and organisation in the UK's magazine publishing industry. Since the mid 1980s, the process of producing magazines has been transformed by the introduction of computer-based technology, the impact of which was felt in two discrete waves. The first concerned the computerisation of the traditional tasks of magazine origination resulting from the development of desktop publishing (DTP) software packages from the mid 1980s, allied to developments in microcomputers, laser printing and the digitisation of fonts. This critical group of process innovations effectively projected publishing into the electronic age. The second impact arose as part of the communications revolution that has changed working and organisational practices across industries generally, and in magazine publishing have allowed for the development of new working practices through systems of electronic file transfer (Cox and Mowatt, 2003).

The introduction of DPT technology significantly altered working patterns in the industry. Effectively, many tasks that had previously been undertaken by specialists, such as layout and design, typesetting and even printing the final product, were collapsed into an integrated package of activities that could be undertaken by a single worker (Mowatt, 2002). These developments reduced the lead-time required to produce a magazine and enabled relatively small organisations to create a product of reasonable quality. In terms of industry structure, by bringing all the functions of pre-press into the publishing arena, DTP technology acted to disentangle the hitherto totally integrated processes of publishing and printing. For the first time, in the 1990s it became meaningful to analyse working practices in the publishing industry without reference to their print-based counterparts. 


\section{The changing nature of innovation}

The objectives of the questionnaire were to assess the impact of ICT technologies on organisational structures and competitive conditions in the UK magazine publishing industry. Studies focusing on the clothing trade had found changing forms of production and innovation through the use of information networks (Abernathy et al., 1999; Gereffi, 1994). The current survey was designed to continue the earlier research we had undertaken on the food processing and retailing industry which have examined change within UK food manufacture and retailing (Cox et al., 2002; 2003). Our working hypothesis was that the technologies of the information revolution are changing the nature of competitiveness in many industries. These, in turn, are creating new and more complex working arrangements. The key to these changes lies in the growing ability of firms to engage in consumer-driven forms of innovation that require greater flexibility in working practices and rapid response to new customer demands. In our earlier work, we identified the growing importance of inter-firm networks, based around the large supermarkets, in the development and provision of new types of convenience foods. Two different types of networks were identified which we termed networks of control and networks of innovation. The development of these networks was first analysed in a comparative historical framework (Cox et al., 2002) and then in a later study we presented a detailed examination of the operation of these networks (Cox et al., 2003). The role of ICTs in the management of these systems was examined in detail (Cox and Mowatt, 2004).

In our magazine publishing study, we wanted to test whether similar network arrangements were also occurring as a response to technological change in a sector that was clearly undergoing a restructuring (Driver and Gillespie, 1993a; 1993b). Our a priori belief was that networks were indeed becoming more prevalent in the industry, similar in kind but quite possibly different in form to those witnessed in the food industry study.

Our earlier study of food processing and retailing had highlighted a preponderance of inter-firm network arrangement between supermarkets, their suppliers and the providers of ancillary services. What we expected to find in the magazine publishing industry were more individualistic hub and spoke forms of networks based largely on outsourcing of inputs (e.g. journalists) and more direct, practically personal, involvement with carefully segmented narrow groups of consumers. As with the food study, however, we expected that those firms that were able to exert control over the access to vital sources of consumer information would be the main beneficiaries in terms of competitive advantage. Access to critical information would be the main driver of innovation.

The survey had two main objectives. The first objective is to collect new data about the structure and operation of the industry, with a particular focus on the sources of information used to engage in innovation. This exercise aims to describe the industry and practise within it in some detail, providing new evidence on this important sector to the UK economy (DTI, 2002). The second objective was to examine the process of innovation within the industry. 


\subsection{Expectations}

The survey was designed to substantiate our observations of organisation and working practices in the magazine publishing industry and to allow us to report on the contemporary structure of the UK industry. In addition to this, drawing on observations made in earlier work examining innovation networks in the food processing and retailing industries in the UK, we were able to develop some expectations about the operation of the innovation process within the publishing sector.

\section{Expectation one: innovation networks are driven by critical consumer information}

The type of information required to inform innovation activity varied in our study of the innovation networks in the food industry. The final consumer was the key to providing the information that was required to develop and supply new products in the innovation network. In the control network, the customer was the retailer and the information that was critical was information about the supply-chain. From this we can consider the nature of the customer in different magazine markets and the critical sources of information. Consumer magazine publishing will be informed by technological or fashion change and business publishing by targeting specific demographic groups.

Expectation two: different critical sources of information will result in different innovation strategies

If innovation is dependent on critical sources of information, then different magazine publishing sectors will derive their information from different areas. Consumer firms will place more emphasis on qualitative research and direct research such as links with experts. Business publishers will be more reliant on quantitative research (about demographic groups) and external agencies.

\section{Expectation three: innovation is reliant on appropriate distribution channels}

If consumer contact is critical to the type of information required for the product and consequently to the innovation process, then it can be posited that reaching consumers is also important. Retail channels are therefore an important consideration. We suggest that consumer magazines will give more priority to retail channels in proximity to end consumers: newsagents, retail chains such as WHSmith and Supermarkets. Business magazines will place more emphasis on subscriptions and internet editions.

Expectation four: critical source of information will be exploited for the provision of related goods and services

The nature of information that drives innovation will also suggest different possibilities for wider exploitation. We suggest that consumer publishers will be able to leverage their critical information to supply services such as TV, radio, internet advertising, licensing and direct involvement with readers' activities. Critical business information will lend 
itself to internet direct sales, fairs and exhibitions. Contract printers will offer contract services.

Our questionnaire sought to elicit responses from a broad range of magazine producers on issues of innovation and organisation. In terms of innovation, a series of questions mostly requiring semantic differential responses were used to gain evidence relating to a range of innovative activity including the form of innovation, the extent of new product launches, the drivers of innovation and the internal sources of ideas and decision-making, regarding innovation activities. With respect to organisational factors, the questionnaire looked at the organisation of various production tasks and methods of communication between publishers and their suppliers and customers. Questions were also included that dealt with the methods of distribution of the magazine content.

\section{The sample}

The questionnaire was developed in conjunction with the UK's main trade body for the magazine industry, the Periodical Publishers' Association (PPA) and was piloted towards the end of 2001 through consultation with seven individuals who had accumulated many years' experience of the magazine publishing industry. Using membership data from the PPA the revised questionnaire and a SAE were mailed in November 2001 to 287 named individuals who held positions (generally senior editorial management and publications directors) which suggested that they would be qualified to express considered views on the issues in hand. The 287 individuals ranged across 261 companies in a total of 246 publishing firms (firms such as IPC and EMAP comprise of a group of distinct companies or operating enterprises). A second mail-out was conducted in February 2002 with follow-up telephone calls. We had hoped that some questionnaires could be completed via the telephone, but this proved effectively impossible to do. Ultimately, 57 valid responses were obtained, giving the study response rates of $20 \%$ by individual, $22 \%$ by company and $23 \%$ by firm.

The response rate and possible bias introduced by the self-selected sampling method demanded closer examination of the sample. An attempt was made to discover how representative the study sample was, relative to the target population in terms of basic demographic variables. The PPA list of UK publishers was chosen as a suitable sampling frame and a simple random sample of size 57 was chosen from this list. The aim of a second sample was to compare the study sample (self-selected). with the random sample in terms of turnover and staffing. The frame consisted of details of current yearly turnover (in millions of pounds) and current staffing levels derived from the FAME database. Altogether, turnover data could be traced on the PP A list for 30 firms of the study sample (29 firms of random) and employee data was recorded for 27 firms in the study sample (26 firms in random sample). This provided evidence of some consistency between the two samples. A Mann-Whitney $U$ test on the data obtained from the PP A list was conducted to evaluate the hypothesis that the study sample has a different turnover, on the average, to the randomly selected sample of firms. The result of the test was not significant $(z=-0.15, p($ exact $)=0.988)$. The same test for difference in average staffing was also found to be not significant $(z=-0.32, p($ exact $)=0.749)$. Further, a 
comparison of quartiles revealed similar variability in turnover and staffing for both samples. In summary, there appears to be little, if any, evidence that the study sample is different in terms of these demographic variables from a random sample. This result, together with the sample profile examination indicates that the study sample is reasonably representative of the magazine publishing sector in the UK.

The basic profile of the sample could be measured using a variety of dimensions. Essentially, the industry as a whole can be broken down into three segments: consumer magazines, business to business and contract publishers. Respondents were asked to indicate which segment(s) they belonged to (Table 1) and for the purposes of analysis were allocated to one of the main segments by inspection (Table 2).

Table 1 Breakdown of respondents by areas of activity

\begin{tabular}{lcc}
\hline Segment $(s)$ & Number of respondents & Percentage $(\%)$ \\
\hline Business only & 23 & 40 \\
Consumer only & 20 & 35 \\
Contract only & 5 & 9 \\
Mixed & 9 & 16 \\
\hline Total & 57 & 100 \\
\hline
\end{tabular}

Table 2 Breakdown of respondents by leading area of activity

\begin{tabular}{lcc}
\hline Main segment & Number of respondents & Percentage (\%) \\
\hline Business & 24 & 42 \\
Consumer & 27 & 47 \\
Contract & 6 & 11 \\
\hline Total & 57 & 100 \\
\hline
\end{tabular}

Two further dimensions of the firm population were measured relating to the number of employees and the international status. The results, shown as a cross tabulation in Table 3 , indicate a good spread across each of the categories of size and status. UK domestic firms tended to cluster at the smaller end of the employee size range, with 19 out of 24 reporting 50 or less employees. In terms of international firms, those featuring a headquarters in the UK were spread fairly evenly across the full-size range of the spectrum, whilst subsidiaries of foreign owned firms clustered in the mid-size range. 
Table 3 Breakdown of respondents by international status and number of employees

\begin{tabular}{lcccc}
\hline Employees & Foreign owned & UK MNCs & UK only & All firms \\
\hline $1-10$ & 0 & 1 & 4 & 5 \\
$11-20$ & 0 & 6 & 5 & 11 \\
$21-50$ & 4 & 5 & 10 & 19 \\
$51-100$ & 4 & 3 & 3 & 10 \\
$101-400$ & 1 & 6 & 1 & 8 \\
Above 400 & 0 & 3 & 1 & 4 \\
\hline All firms & 9 & 24 & 24 & 57 \\
\hline
\end{tabular}

\section{Indicators of innovation}

The most conventional measure of product innovation within the magazine industry has traditionally been new title launches. A recent study by the DTI and PIRA (DTI, 2002) shows that since 1993 new launches in the consumer magazine branch of the industry have been running at an average annual rate of around 600 titles. Allowing for closures, this process of innovation has raised the total number of magazine titles in circulation from just over 2,000 to well over 3,000 by the year 2000 (DTI, 2002, Figure 8.6). In the more extensive range of business to business titles, a sharp rise in the number of titles was also experienced from around 4,700 to well in excess of 5,000 between 1997 and 2000 (DTI, 2002, Figure 9.2). Amongst our sample, we found that 40 out of the 57 respondents $(70 \%)$ claimed to have launched at least one title during the past two years, whilst 27 firms (47\%) had closed at least one title during the same period (Table 4). New title launches were spread quite evenly across the segments of the industry, with firms claiming to have launched at least one new title during the preceding year figuring across all segments. As Table 5 shows, it was firms producing consumer magazines only, that displayed the lowest response whilst all 5 contract-only publishers had launched at least one new title. Amongst the firms who claimed to have initiated two or more new product launches during the last two years, all of them had launched at least one title within the space of the preceding twelve months (Table 6). This gives our sample a group of 22 firms that we have designated as the leading' new product innovators' .

Table 4 Launching and closing of titles in previous two years

\begin{tabular}{lcc}
\hline No of titles & Titles launched in previous two & Titles closed in previous two \\
& years & years \\
\hline None & 17 & 30 \\
One & 18 & 12 \\
Two or Three & 10 & 8 \\
Four or more & 12 & 7 \\
\hline
\end{tabular}


Table 5 New title launches in last 12 months by industry segment

\begin{tabular}{lcc}
\hline Segment & $\begin{array}{c}\text { Launched at least one new } \\
\text { title in previous 12 months }\end{array}$ & $\begin{array}{c}\text { Percentage of total respondents in } \\
\text { category }(\%)\end{array}$ \\
\hline Business-only & 13 & 57 \\
Consumer-only & 6 & 30 \\
Contract-only & 5 & 100 \\
Mixed & 6 & 67 \\
\hline All respondents & 30 & 53 \\
\hline
\end{tabular}

Table 6 New titles launched by number and duration

\begin{tabular}{lcc}
\hline & \multicolumn{2}{c}{ Number of titles launched in last two years } \\
\hline Most recent launch & Two or more & One \\
Within 6 months & 14 & 5 \\
Within year & 8 & 3 \\
Within 2 years & & 10 \\
\hline Total & 22 & 18 \\
\hline
\end{tabular}

The responses relating to new title launches suggest that this form of innovation is widespread across the different types of firms in the magazine publishing industry. However, it is not necessarily the case that the motive for this type of innovation is always the same, and our questionnaire asked the respondents to identify the importance of different drivers. It was suggested that industry-led new title innovation based around advertising-specific demographic groups would provide one motive. Alternatively, a more consumer-driven motive for new title launches was felt to be external drivers such as fashion or technological change, as outlined in expectation two. The results, presented in Table 7, illustrate that demographic factors were a common driving force for innovation amongst the respondents as a whole. In contrast, the impact of fashion and technological change was far more mixed.

Table $7 \quad$ Key drivers of new title launch

\begin{tabular}{lcccc}
\hline Key Driver & Irrelevant & Unimportant & Of some importance & $\begin{array}{l}\text { Very } \\
\text { important }\end{array}$ \\
\hline Fashion/technology & $9(17 \%)$ & $6(11 \%)$ & $32(59 \%)$ & $7(13 \%)$ \\
Demographic groups & $3(6 \%)$ & $3(6 \%)$ & $6(12 \%)$ & $41(79 \%)$ \\
\hline
\end{tabular}

The issue of consumer-driven innovation posited in expectation two was further explored with reference to the sources of consumer information that firms exploited. Table 8 shows that the majority of respondents used quantitative surveys of readers, experts and competitors' moves to identify consumer trends. Information from allied firms (partners and agents) was rarely submitted as being of great importance. By far the most mixed response concerned the use of qualitative surveys (e.g., focus groups), whilst a reasonably mixed picture emerged with respect to the importance of the internet. This leads us to believe that the latter two factors may be of significance in discriminating between the 
more consumer-driven innovators and those innovators whose ideas were driven simply by more conventional demographic, supply-side factors.

Table 8 Sources of consumer information

\begin{tabular}{|c|c|c|c|c|c|}
\hline \multirow{2}{*}{\multicolumn{2}{|c|}{ Information source No titles }} & \multicolumn{3}{|c|}{ Degree of importance } & \multirow[b]{2}{*}{ Index } \\
\hline & & Sor & $M o$ & All titles & \\
\hline Quantitative & 2 & 6 & 18 & 30 & (high) 79 \\
\hline Experts & 4 & 5 & 18 & 29 & (high) 76 \\
\hline Competitors & 6 & 11 & 6 & 33 & (high) 73 \\
\hline Qualitative & 11 & 15 & 16 & 14 & (mixed) 53 \\
\hline Internet & 21 & 18 & 9 & 7 & (mixed) 35 \\
\hline Partners & 19 & 25 & 4 & 5 & (low) 30 \\
\hline External agents & 27 & 21 & 4 & 4 & (low) 24 \\
\hline
\end{tabular}

These findings are interesting to consider in conjunction with forms of innovation other than new title launches. New title launches are a conventional output measure of innovation, as used by the DTI in their recent study of the UK publishing sector (2002). An alternative approach to using one form of output (i.e., new titles) is to obtain a quantum unit of innovation based on the total numbers of all products and process innovations without differentiating between the form which these innovations may take, as in the Community Innovation Surveys (Thomas and Jones, 1998). In addition to considering a simple output measure of innovation (new titles) or an aggregate of all value-adding activities we decided to establish the range of activities that magazine companies could undertake to explore expectation four. Table 9 itemises twelve forms of activity that publishers have used to develop their magazine brands. Two areas of significant growth during the survey period can be seen to be the provision of internet services for third parties and direct involvement with readers. In both of these activities, an ongoing dialogue with consumers is particularly important. However, only five firms (around a quarter of each group) claimed to have actually engaged in both of these activities, suggesting that they represent different consumer-driven strategies. Indeed, in all but one of these categories, the group of 22 'new product innovators' were no more likely to have undertaken the activity in question than other respondents (might be worth testing for just the non-innovators). Innovation in magazine publishing thus appears to be both widespread and multi-faceted. 
Table 9 Forms of innovation other than new title launches

\begin{tabular}{llll}
\hline \multicolumn{1}{c}{ Innovation form } & $\begin{array}{c}\text { More than two } \\
\text { years ago }\end{array}$ & $\begin{array}{c}\text { Within last two } \\
\text { years }\end{array}$ & Plan to introduce \\
\hline TV channel & 1 & 2 & 3 \\
Radio station & 0 & 2 & $\mathrm{I}$ \\
Internet advertising & 15 & 13 & 2 \\
Internet sales/subscriptions & 8 & 10 & 1 \\
Internet services for third parties & 4 & 12 & 3 \\
Marketing services & 10 & 7 & 1 \\
Licensing of titles & 8 & 4 & 4 \\
Contract printing services & 8 & 9 & 1 \\
Event sponsorship & 14 & 7 & 2 \\
Fairs/ exhibitions & 12 & 11 & 2 \\
Direct involvement with readers & 7 & 11 & 2 \\
Telephone services & 6 & 5 & $\mathrm{I}$ \\
\hline
\end{tabular}

\section{Organisation, communication and distribution}

The impact of the DTP revolution on the organisation of magazine publishing firms was felt particularly in respect of art, design and layout. Prior to the DTP revolution, these tasks were discrete activities undertaken by specialists. However, with the availability of new software packages, these tasks effectively became integrated with the process of text inputting. As a result, many of the independent firms who had previously specialised in these areas of the publishing process were no longer required. Of the 57 firms who responded to the questionnaire, 50 replied that all their requirements for art, design and layout were undertaken entirely in-house, and five of the remaining seven used a mixture of internal and external. Ten years previously, over $20 \%$ of the firms in the survey used outside firms exclusively to undertake these tasks.

Whilst the creative processes relating to layout tend to have been absorbed into publishing companies, many of the tasks relating to the provision and editing of text have been outsourced. Table 10 shows that contract staff, commission only and external agencies play an important role in the core tasks of content provision and editing. It is true that editing tasks are almost always managed, if not always performed, by in-house staff, but the provision of features is not infrequently entirely outsourced. In the case of occasional or special features, 18 of the 55 respondent firms claimed never to use inhouse staff for this activity, whilst two thirds used the services of commission-only providers. This process of outsourcing has given magazine publishers much more flexible writing capacity and made it much easier for them to respond to topical events with special issues of their leading titles. Ease of communication has been a significant factor in promoting this greater flexibility. 
Table 10 Organisation of magazine production tasks

\begin{tabular}{llllll}
\hline Task & In-house staff & $\begin{array}{l}\text { Contract } \\
\text { staff }\end{array}$ & $\begin{array}{l}\text { Commission } \\
\text { only }\end{array}$ & $\begin{array}{l}\text { External } \\
\text { agency }\end{array}$ & $\begin{array}{l}\text { Total number } \\
\text { of responses }\end{array}$ \\
\hline Editorial tasks & 53 & 23 & 13 & 2 & 56 \\
Copy editing & 54 & 12 & 4 & 1 & 55 \\
Main features & 47 & 23 & 23 & 3 & 54 \\
Regular features & 50 & 18 & 19 & 2 & 55 \\
Occasional/specials & 37 & 24 & 33 & 3 & 55 \\
News editing & 51 & 9 & 4 & Nil & 53 \\
\hline
\end{tabular}

Table 11 shows that publishers have a clear preference for receiving copy in electronic format, although at present a variety of transfer systems continue to be used. A similar pattern is also true of the copy received from advertisers although in this area, publishers hold a much weaker bargaining position than with the fragmented feature copy providers. Practically $80 \%$ of publishers reported receiving advertising copy by post in spite of a clear preference for electronic forms of transfer.

Table 11 Receiving information from contributors and advertisers

\begin{tabular}{lcccc}
\hline \multirow{2}{*}{ Transfer mechanism } & \multicolumn{2}{c}{ Contributors } & \multicolumn{2}{c}{ Advertising Copy } \\
& In use & Preferred & In use & Preferred \\
\hline In office & 24 & 1 & 7 & Nil \\
Hardcopy (post) & 25 & 4 & 41 & 5 \\
Hardcopy (fax) & 24 & 2 & 27 & 1 \\
Electronically (disk by post) & 31 & 12 & 36 & 15 \\
Electronically (e-mail) & 46 & 36 & 38 & 34 \\
Total respondents & 55 & 41 & 54 & 41 \\
\hline
\end{tabular}

Even before DTP, only the largest magazine publishing firms undertook their own printing. However, the working practices in that industry placed heavy restrictions on the process of magazine publishing, involving extremely detailed demarcation between tasks. DTP enabled the publishing houses to provide printers with print-ready copy and the ICT revolution has enabled radical alterations in the method by which this copy is supplied. Table 12 shows that 26 out of the 57 respondents (46\%) now send copy to their printers exclusively by electronic means. As recently as two years ago, less than $10 \%$ of the respondents used these methods exclusively. The processes of deep physical integration that traditionally bound together publishers and printers through working practices is now being replaced by an information-based system of integration that emphasises speed sometimes at the expense of accuracy. 
Table 12 Method of supplying copy to printers

\begin{tabular}{lcc}
\hline Method of supply & Two years ago & Now \\
\hline Physically (e.g. film by post/couriers) & 40 & 31 \\
By EDI or integrated network linkages & 9 & 43 \\
Electronically through public systems & 4 & 23 \\
Only electronically & 4 & 26 \\
Total respondents & 44 & 57 \\
\hline
\end{tabular}

To date, the emergence of ICT in the form of websites has not led to a transition from paper-based to electronic copy systems of provision. Magazine publishers were guilty parties in the dot.com bubble of the late 1990s as they poured resources into the setting up of elaborate websites that had no meaningful income-generating capacity. Fear of 'cannibalisation' drove this process, as magazine producers anticipated (or at least felt obliged to prepare themselves for the possibility of) a shift towards an electronic medium of content provision. Web sites are now being used more selectively, in an effort to provide a complementary form of access to readers rather than a simple alternative. An upshot of this is the continuing importance of the retail trade in the process of physical distribution, as anticipated by expectation three. Table 13 demonstrates that the system of retail distribution remains very similar to that which operated ten years ago. The retailers themselves, whilst irrelevant to some publishers, still play an important function in the magazine industry, with very few firms rating them as unimportant (Table 14). From this it is also evident that subscription sales remain very important to most magazine publishers, but that the internet is still to come of age as a retailing platform. The new force in distribution over the last ten years or so has been the supermarkets, whose shelf space has become a critical factor for popular consumer magazines purchased from the stands. There is some recent evidence that retailers can exert power over suppliers in the supply-chain that may affect innovation and investment (Dobson et al., 1998). Asked whether supermarket power is an impediment to innovation, around $43 \%$ of respondents agreed in the case of new titles, and 33\% in the case of new services.

Table 13 Distribution to retailers

\begin{tabular}{lcc}
\hline & Ten years ago & Now \\
\hline Own distribution & 3 & 6 \\
Big 3* & 19 & 23 \\
Other external & 5 & 9 \\
Retailer/client direct & 4 & 4 \\
Total respondents & 25 & 17 \\
\hline
\end{tabular}

*Surridge-Dawson; John Menzies; WHSmith Distribution. 
Table 14 Importance of different retail channels

\begin{tabular}{lccccc}
\hline Channel & Irrelevant & Unimportant & $\begin{array}{l}\text { Some } \\
\text { importance }\end{array}$ & $\begin{array}{l}\text { Very } \\
\text { important }\end{array}$ & Respondents \\
\hline $\begin{array}{l}\text { Independent } \\
\text { newsagents }\end{array}$ & 17 & 3 & 11 & 22 & 53 \\
WHSmith & 18 & 1 & 11 & 23 & 53 \\
Supermarkets & 23 & 6 & 9 & IS & 53 \\
Subscription & 3 & 3 & 17 & 30 & 53 \\
Internet & 6 & 16 & 22 & 8 & 52 \\
Single outlet & 20 & 8 & 14 & 11 & 53 \\
$\begin{array}{l}\text { Controlled } \\
\text { circulation }\end{array}$ & 12 & 6 & 7 & 28 & 53 \\
\hline
\end{tabular}

\subsection{Developing a picture of the innovation space}

The aim of studies examining innovation is generally to develop an understanding of the drivers of innovation. In addition, the significance of innovation to an industry, generally taken as the amount of innovation, is often viewed as important. Within the current data set, new title launches as a measure of innovation do not reveal any significant drivers of innovation in the data. The question must be asked however as to the usefulness of a simple measure which may overlook the range of activities available to firms in their industry. In order to develop a more subtle understanding of the innovation process in the sector, we have employed correspondence analysis. This is a useful exploratory technique that helps to provide a clearer picture of the nature of the relationship between two variables. In the present study, the two variables business category and services introduced were cross tabulated and a chi-square test of independence revealed a significant association between the two. The chi-square test does not reveal the dependence structure, and it is difficult to discern which categories of services introduced are associated most strongly with the business segment. We then decided to explore new methods for examining the relationship between variables. Correspondence analysis facilitates an examination of the relationship between two nominal variables graphically in multidimensional space. Categories that are similar to each other appear close to each other in a plot. In this way it can be seen which categories of services introduced are similar to each other, and whether categories of services introduced are related to categories of business segment. The measure of correspondence may be an indication of the similarity, association, affinity or interaction between the row and column variables.

In summary, the goal of correspondence analysis is to describe the relationships between two nominal variables in a low-dimensional space, while simultaneously describing relationships between the categories for each variable.

Distances between category points in a plot reflect the relationships with similar categories plotted close to one another. Projecting points for one variable on the vector from the origin to a category point for the other variable describe the relationship 
between the variables. In Figure 1, symmetrical normalisation has been used. This is appropriate if we are primarily interested in the relationships between the two variables. Usually, this is the preferred method to make biplots (Heiser and Meulman, 1993).

Figure 2 shows a column principal normalisation. This method maximises the distances between the columns (in this study the business segment) and should be used if the primary interest is how business segments differ from each other. Note that Everitt proposes correspondence analysis as an 'extremely useful supplement to, rather than a replacement for, a more formal log-linear or logistic model' (Everitt and Dunn, 2001).

It is more of an exploratory technique, providing a visual picture/appreciation of relationships.

Figure 1 Mapping the innovation space of the magazine publishing industry with correspondence analysis: symmetrical normalisation

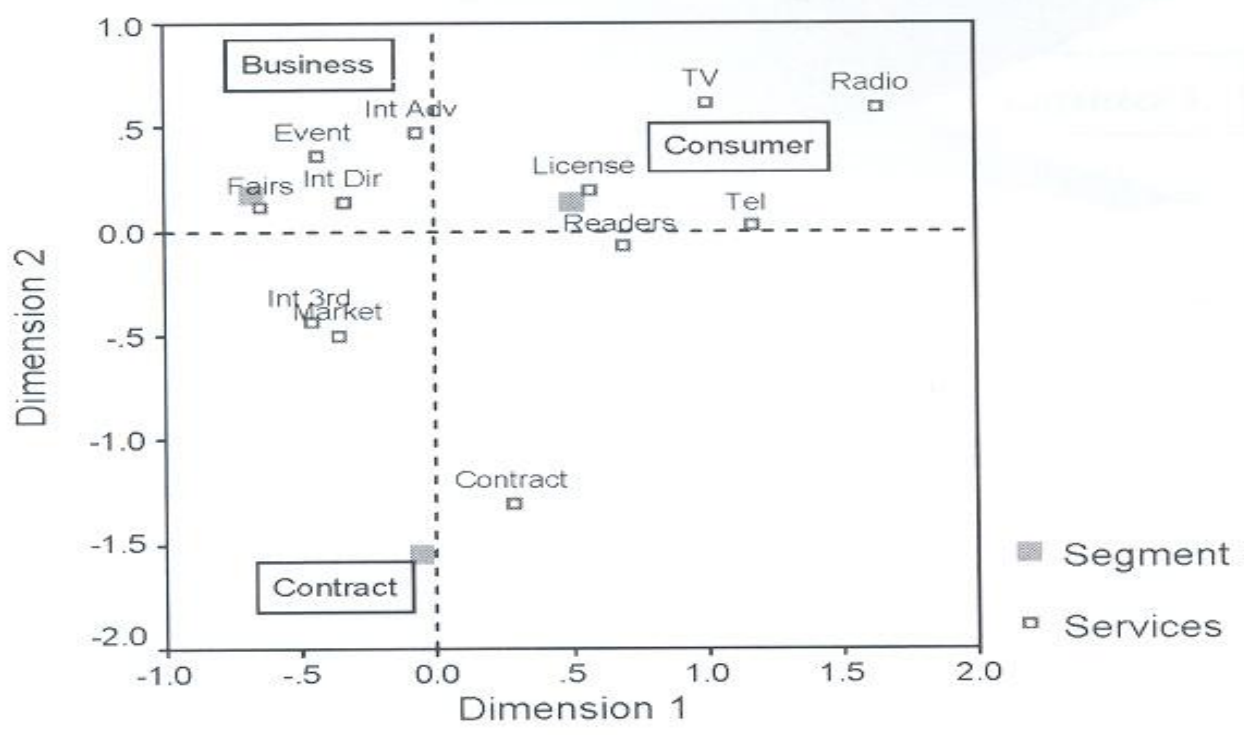


Figure 2 Technological and fashion change as a driver of innovation: in relation to the number of new titles by publishing firms

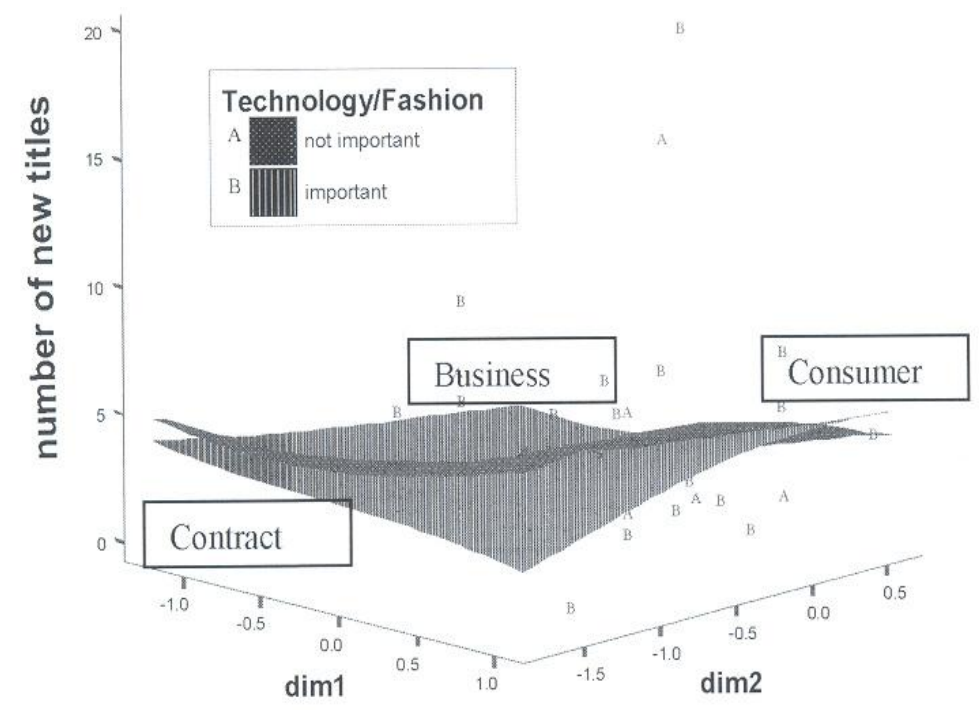

Figure 1 shows the relationship between activities undertaken by respondents. The figure outlines innovation activities and finds that in general, firms undertaking a group of activities are generally from one sub sector, such as the consumer. Any individual firm can be located in this innovation space by its individual survey response: therefore a selfdeclared business sector firm may undertake a range of activities associated with the consumer category. We could consider this firm as consumer-driven, using the same strategies as consumer firms.

Figure 3 Technological and fashion change as a driver of innovation: in relation to the type and intensity of activities by publishing firms

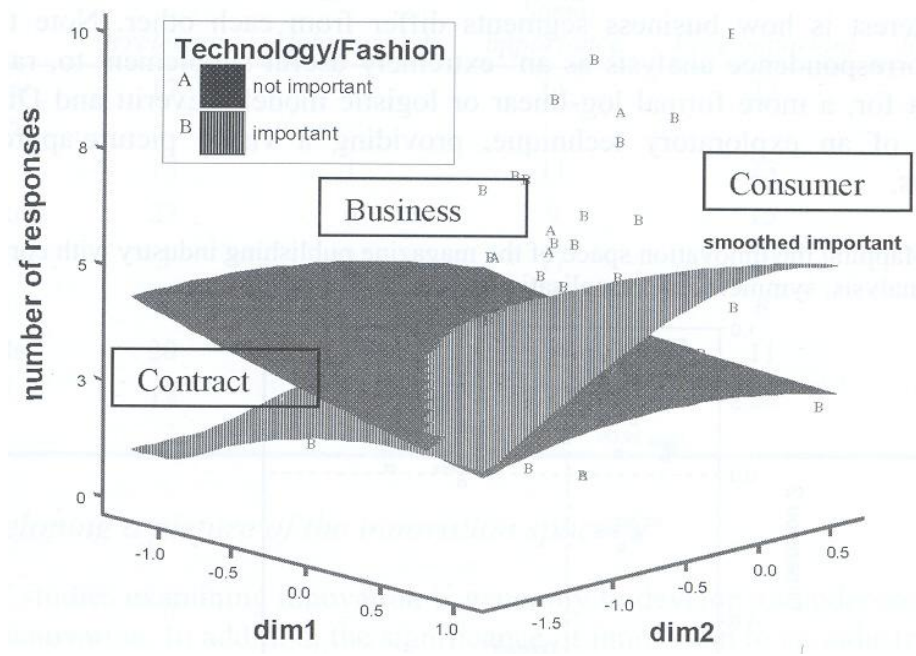


In Figures 2 and 3 we map, in three dimensions, all the individual firms in the sample by their responses to any activity. Therefore each point represents a firm that has a location determined by the range of activities which it engages in, and an intensity (height). Figure 2 shows intensity in terms of the number of titles launched. Figure 3 uses the number of value-adding activities (see Figure I) undertaken. The overall responses are smoothed using a three-firm averaging. In order to use this three dimensional map of the innovation space to examine the drivers of innovation, we can dichotomise between responses to questions concerning the drivers of innovation and the type of information informing innovative activities. Thus in both Figures 2 and 3, the self-reported importance of technological or fashion change is used to discriminate between responses. It would appear to suggest that whilst this is not particularly important in terms of launching new titles (although there is some evidence that this is a factor for consumer firms), it is very important in explaining the number of value-adding activities undertaken by consumer firms. The initial expectations one, two, and four would lead us to expect that innovation strategies within an industry would vary with respect to different drivers of innovation, and result in different patterns of innovation. This is indicated in Figure 3. Although both consumer driven innovation strategies and business-to-business driven strategies result in similar quantum levels of output, the group are clearly divided with respect to the drivers. This can also be linked to the types of innovative activity which demonstrate that the different groups do indeed undertake different forms of innovation as outlined in expectation four.

\section{Commentary on results}

Several exploratory approaches have been used to analyse the data in this study. An initial approach (not outlined in this paper due to space limitations) examined the sample using titles launched as a measure of innovation, as used in the DTI study (2002). This approach proved not to reveal many significant linkages between drivers of innovation, sources of information or the range of activities undertaken (although there were some significant correlations in this area). The question as to whether titles launched is an useful measure of innovation in this sector can be questioned in any case, and the correspondence analysis (Figure 2) shows that new titles is a poor discriminator of innovative activity. Correspondence analysis proved a useful empirical way of confirming that our initial expectation four was correct in predicting which value-adding activities would be undertaken by which sector. This approach also allowed us to dichotomise responses to the number of new titles and range of innovative activities undertaken to reveal whether factors were important or not for these firms. Figure 2 shows, for example, that consumer driven firms who undertook a large number of innovative activities in their area (as shown in Figure 1) answered that fashion and technological changes were very important as drivers for innovation. It can be seen that those consumer firms who answered negatively undertook a much smaller number of innovative activities. For the business sector this was a much less important factor even though the number of innovative activities was quite high. The same exercise using demographic groups as the dichotomy show the opposite trend than that expected. This may suggest that the aggregate measure of innovation in this example would be able to trace the drivers of innovation because they are different between the market sectors and 
for the types of activities within them, as predicted in expectation two. Finally expectation three, that retail channels would be important for consumer publishers was supported. In the initial analysis, using only titles launched to create an innovative group of firms (those with more than two launches in the last six months), showed a significant correlation with retail channels. This result was clearer with correspondence analysis where there was a clear discrimination between the importance of retail channels to consumer firms (figure not reproduced here).

\section{Conclusion}

In conclusion, this survey has attempted to present new information about the operation of the publishing sector and to analyse the nature of innovation in the magazine publishing industry. The survey confirms that working practices within the industry have changed in the last decade with the internalisation of design and the outsourcing of printing, and that the use of electronic copy has become more prevalent. The concept of innovation and measurement is discussed and the question addressed as to whether innovation be captured by a simple measure such as title launches. The evidence presented here suggests that title launches by itself, only reflects one aspect of the activities undertaken by magazine publishing houses which could be viewed as the innovative or value-adding activities and that the innovation process is more subtle. Firms innovate products and services in addition to new titles and the drivers behind new products and services vary. From this it could be suggested that simple measures of innovation provide a weak basis for exploring the drivers of innovation as they fail to capture the heterogeneity of the new developments. The survey analysis also suggests that the nature of activity undertaken varies from sub sector to sub sector within the industry. The suggestion is made here that the role of the end consumer and the nature of the information required to provide services for consumers is the determinant of the type of activities entered into. The concept of developing an industries 'innovation space' through correspondence analysis as a basis for examining the scale and location of innovation is suggested as meriting further research. In particular, the ability to reveal the drivers of innovation behind different types of value-adding activities may have further application in the design of future research in the industry which could test this exploratory data in a more quantitative way. Further research is required to first establish the robustness of the approach suggested, and also to examine whether the innovation space approach is a suitable one for the analysis of other industrial areas.

\section{Acknowledgements}

The authors would also like to extend their thanks to the Leverhulme Trust for providing an Institutional Grant that supported the empirical work drawn on for this paper. Thanks also to the pp A for supporting this study through the use of their membership database and to all the respondents to this large questionnaire. 


\section{References}

Abernathy, F.H. et al. (1999) A Stitch in Time: Lean Retailing and the Transformation of Manufacturing - Lessons from the Apparel and Textile Industries, Oxford University Press, New York.

Cox, H. and Mowatt, S. (2003) 'Technology, organisation and innovation: the historical development of the UK magazine industry', Enterprise and Innovation: Research Papers of the AUT Faculty of Business paper 04-2003 (ISSN 1176-1997).

Cox, H. and Mowatt, S. (2004) 'Consumer-driven innovation networks and e-business management systems', Qualitative Market Research: An International Journal, Vol. 7, No. 1, pp.9-20.

Cox, H., Mowatt, S. and Prevezer, M. (2002) 'The firm in the information age: organizational responses to technological change in the processed foods sector', Industrial and Corporate Change, Vol. 11, No. 1, pp.135-158.

Cox, H., Mowatt, S. and Prevezer, M. (2003) 'New product development within a network setting: the case of the chilled ready-meals industry in the UK', Industry and Innovation, Vol. 10, No. 2, pp.197-217.

Dobson, P., Waterson, M. and Chu, A. (1998) The Welfare Consequences of the Exercise of Buyer Power, Office of Fair Trading Research Paper 16.

Driver, S. and Gillespie, A. (1993a) 'Structural-change in the cultural industries - British magazine publishing in the 1980s' Media Culture \& Society, Vol. 15, No. 2, pp. 183-201.

Driver, S. and Gillespie, A. (1993b) 'Information and communication technologies and the geography of magazine print publishing', Regional Studies; Vol. 27, No. 1, pp.53-64.

DTI (2002) Publishing in the Knowledge Economy: Competitiveness Analysis of the UK Publishing Media Sector, DTI Report, accessed May 1, 2003, available: http://www.uk -publishing. info/competitive.asp.

Everitt, B. and Dunn, G. (2001) Applied Multivariate Data Analysis, Arnold, London.

Gereffi, G. (1994) 'The organization of buyer-driven global commodity chains: how US Retailers shape overseas production networks', in Gereffi, G. and Korzeniewicz, M. (Eds.): Commodity Chains and Global Capitalism, Westport, Conn., Praeger, pp.95-122.

Heiser, W.J. and Meulman, J.J. (1993) Nonlinear Methods for the Analysis of Homogeneity and Heterogeneity, Research Report RR-93-03, Department of Data Theory, University of Leiden, p.39.

Mowatt, S. (2002) 'Technology and industrial change: the shift from production to knowledge-based business in the magazine print publishing industry', in Kantarelis, D. (Ed.): Global Business and Economics Review - Anthology 2002, pp.282-296.

Thomas, M. and Jones, P. (1998) UK Results from the 2nd Community Innovation Survey, Report published by the DTI, accessed June 1999, available: http://www.dti.gov.ukliese/results.pdf.

\section{Note}

The observed cell frequencies differ significantly from the expected values at the 5\% level $(\operatorname{chi} \operatorname{sq}(22)=35, P=0.35)$. 